\title{
Experimental Test Bed to Enable Realistic Evaluations for Direct Transfer Trip Relaying via Private Wireless LTE Communications
}

Emma Raszmann, Kumaraguru Prabakar, Barry Mather, Jim Li

September 28 - October 1, 2020

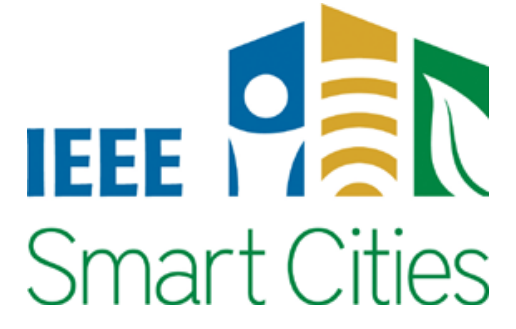




\section{Outline}

\section{Background}

2 Research Objectives

3 Lab Setup

4 Experimental Results

5 Conclusions

6 Q\&A 


\section{Communication for a More Distributed Grid}

\section{A highly distributed grid can result in:}

More complex communications management

More communications congestion

More cybersecurity vulnerabilities

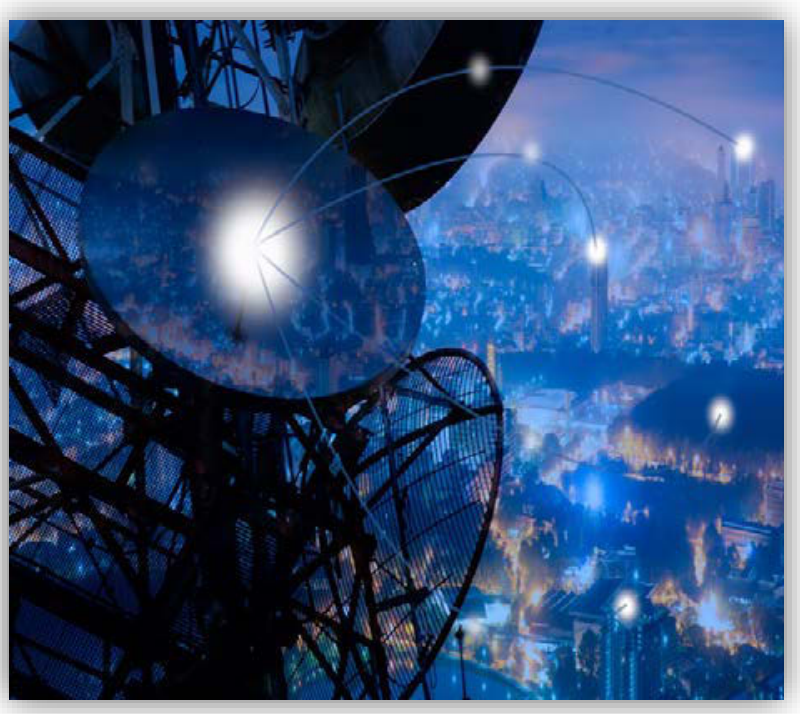

An increase of advanced energy technologies on the grid requires a proportional growth in secure and reliable communications. 


\section{Wireless Communication for Grid Applications}

Wireless communications provide a cost-effective alternative to wired solutions and a higher interoperability for a range of grid devices.

Direct transfer relaying is an example of a grid application where utilities need a dependable and low latency wireless communication solution in order to send a trip signal to a remote or far away location.

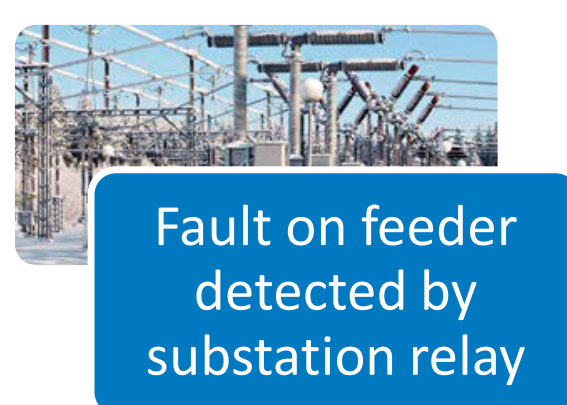

An example ${ }^{1}$ :
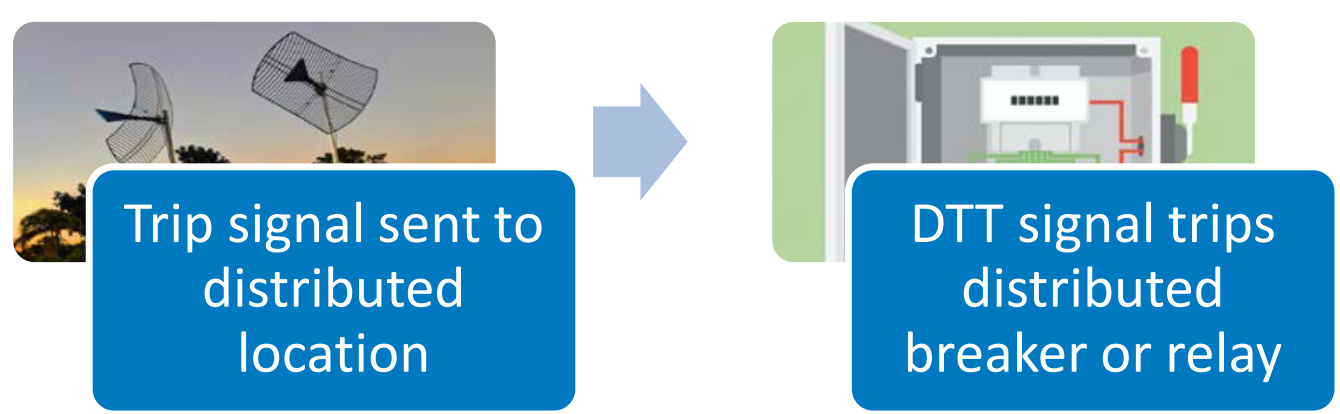


\section{Research Objectives}

\section{Objectives}

- Develop an evaluation platform to study the impact from wireless communication in a low-latency grid application.

- De-risk wireless communications for utilities facing high levels of distributed energy resource integration.

\section{Method}

- Evaluate direct transfer trip (DTT) events using a private wireless LTE system integrated with a PV inverter \& load system.

Wireless Scenarios Under Test

- Strong vs. weak LTE signal propagation

- Traffic load vs. no traffic load

- High vs. low priority air-interface traffic queuing 


\section{Lab Setup and Measurement}

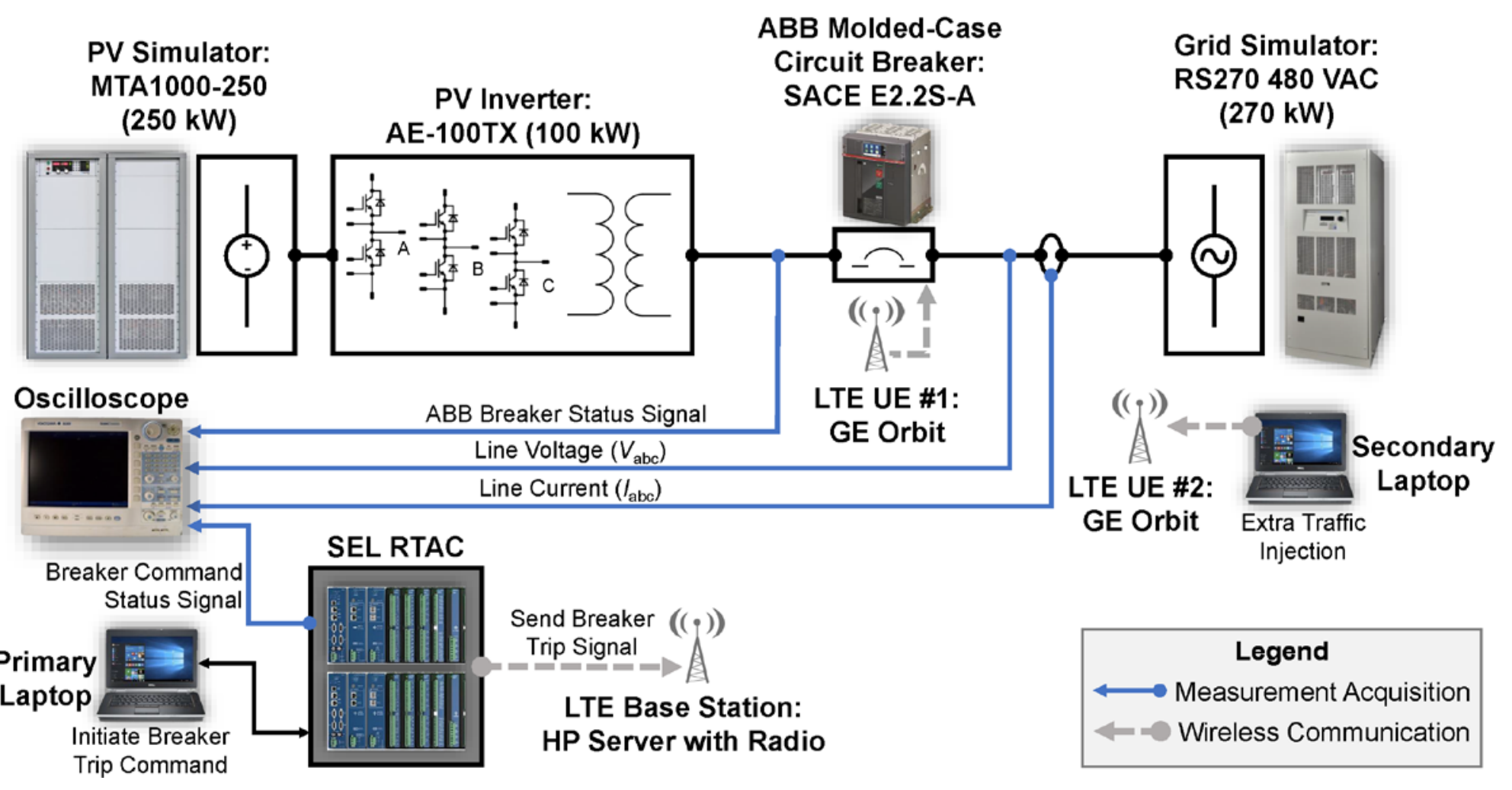




\section{Lab Setup and Measurement - continued}

\section{Private LTE Network Setup at NREL's Energy Systems Integration Facility}

LTE Wireless

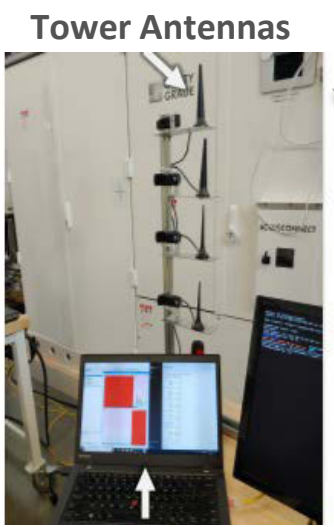

LTE Endpoint Antennas
Wireless

\section{Communication}



LTE Gateway Access Endpoint Equipment
DTT timing is calculated between when the trip signal was sent to when the line current downstream of the breaker drops to $0 A$.

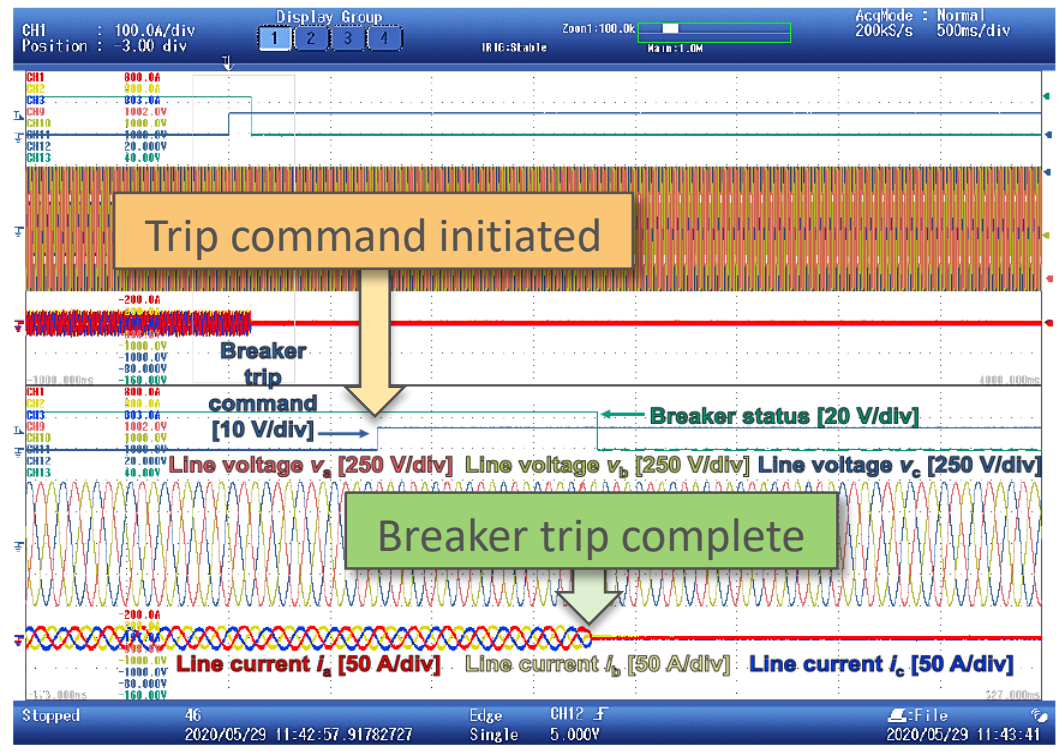




\section{Experimental Results}

\section{- A total of 7 different}

wireless scenarios were studied in a DTT application.

- The 7 wireless scenarios were performed 10 times each to strengthen the statistical confidence of the results.

\section{Latency Calculations for Direct Transfer Trip Experiments}






\section{Key Trends in Results}

Latency Calculations for Wireless Direct Transfer Trip Experiments

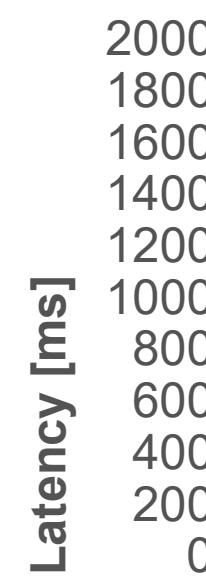

The low priority breaker communication scenarios (IV \& VII) resulted in the highest latency and widest range in DTT timing.

For high priority breaker communication scenarios (III $\&$ VI), the attenuated wireless scenario had $50.08 \%$ greater range in timing compared to wireless without attenuation. $\square$ Average Time until Trip

$\square$ Minimum Time until Trip

$\square$ Maximum Time until Trip 


\section{Conclusions}

1. An evaluation framework was developed for validating private LTE wireless communication performance for grid applications such as DTT.

2. Private LTE wireless technologies are capable of protection for distributed applications.

3. Message prioritization has large impact on communication timing; hence, control of queuing is key component for critical infrastructure applications. 


\title{
Thank You.
}

\section{www.nrel.gov}

\author{
NREL/PR-5D00-77958
}

This work was authored in part by the National Renewable Energy Laboratory, operated by Alliance for Sustainable Energy, LLC, for the U.S. Department of Energy (DOE) under Contract No. DE-AC36-08G028308. Funding provided by the U. S. Department of Energy, Office of Energy Efficiency and Renewable Energy via the Energy Systems Integration Facility. The views expressed in the article do not necessarily represent the views of the DOE or the U.S. Government. The U.S. Government retains and the publisher, by accepting the article for publication, acknowledges that the U.S. Government retains a nonexclusive, paid-up, irrevocable, worldwide license to publish or reproduce the published form of this work, or allow others to do so, for U.S. Government purposes. 


\section{Paper References}

1. U.S. Department of Energy, "Grid Modernization Multi-Year Program Plan," https://www.energy.gov/downloads/grid-modernization-multi-year-program-plan-mypp, 2015.

2. K. P. Schneider, S. Laval, J. Hansen, R. B. Melton, L. Ponder, L. Fox, J. Hart, J. Hambrick, M. Buckner, M. Baggu et al., "A distributed power system control architecture for improved distribution system resiliency," IEEE Access, vol. 7, pp. 9957-9970, 2019.

3. A. Maitra, A. Pratt, T. Hubert, D. Wang, K. Prabakar, R. Handa, M. Baggu, and M. McGranaghan, "Microgrid Controllers: Expanding Their Role and Evaluating Their Performance," IEEE Power and Energy Magazine, vol. 15, no. 4, pp. 41-49, 2017.

4. D. Whitehead and R. Smith, "Cryptography: A tutorial for power engineers," in proceedings of the 35th Annual Western Protective Relay Conference, Spokane, WA, 2008.

5. J. Pacheco, C. Tunc, and S. Hariri, "Design and evaluation of resilient infrastructures systems for smart cities," in 2016 IEEE International Smart Cities Conference (ISC2), 2016, pp. 1-6.

6. I. Jawhar, N. Mohamed, and J. Al-Jaroodi, "Networking and communication for smart city systems," in 2017 IEEE Smart-World, Ubiquitous Intelligence Computing, Advanced Trusted Computed, Scalable Computing Communications, Cloud Big Data Computing, Internet of People and Smart City Innovation (SmartWorld/SCALCOM/UIC/ATC/CBDCom/IOP/SCI), 2017, pp. 1-7. 


\section{Paper References}

7. T. M. Chen, "Smart grids, smart cities need better networks [Editor's Note]," IEEE Network, vol. 24, no. 2, pp. 2-3, 2010.

8. S. V. Achanta, R. Bradetich, and K. Fodero, "Speed and security considerations for protection channels," in 2016 69 $9^{\text {th }}$ Annual Conference for Protective Relay Engineers (CPRE). IEEE, 2016, pp. 1-9.

9. J. Simms and G. Johnson, "Protection considerations for installation of distributed energy resources," in 2015 68th Annual Conference for Protective Relay Engineers. IEEE, 2015, pp. 289-301.

10. P. J. Zawada, "A survey of substation communications technology," in 2000 Power Engineering Society Summer Meeting (Cat. No. 00CH37134), vol. 1. IEEE, 2000, pp. 573-578.

11. M. S. Obaidat, A. Anpalagan, and I. Woungang, Handbook of green information and communication systems. Academic press, 2012.

12. V. Namboodiri, V. Aravinthan, S. N. Mohapatra, B. Karimi, and W. Jewell, "Toward a secure wireless-based home area network for metering in smart grids," IEEE Systems Journal, vol. 8, no. 2, pp. 509-520, 2013.

13. F. Shariff, N. A. Rahim, and W. P. Hew, "Zigbee-based data acquisition system for online monitoring of gridconnected photovoltaic system," Expert Systems with Applications, vol. 42, no. 3, pp. 1730-1742, 2015. 


\section{Paper References}

14. F. Aalamifar and L. Lampe, "Optimized wimax profile configuration for smart grid communications," IEEE Transactions on Smart Grid, vol. 8, no. 6, pp. 2723-2732, 2016.

15. A. R. Khattak, S. A. Mahmud, and G. M. Khan, "The power to deliver: Trends in smart grid solutions," IEEE Power and Energy Magazine, vol. 10, no. 4, pp. 56-64, July 2012.

16. M. Kuzlu and M. Pipattanasomporn, "Assessment of communication technologies and network requirements for different smart grid applications," in 2013 IEEE PES innovative smart grid technologies conference (ISGT). IEEE, 2013, pp. 1-6.

17. T. Fix, A. Smit, S. Chanda, and J. A. Key, "New Intelligent Direct Transfer Trip Over Cellular Communication," in 2019 72nd Conference for Protective Relay Engineers (CPRE), March 2019, pp. 1-9. 